\title{
Childhood hypertrichosis: diagnosis and
} management

\author{
F A M Baumeister, H P Schwarz, S Stengel-Rutkowski
}

There is wide variation in the normal pattern of hair growth. Hypertrichosis, which can be defined as excessive growth of hair compared with that in other subjects of the same age, sex, and race, must be distinguished from hirsutism, a term restricted to an androgen dependent hair pattern that is characterised by excessive hair growth on the upper lip, chin, chest, linea alba, thighs, and axillae. Unlike hypertrichosis, unexplained hirsutism in childhood usually warrants investigation to exclude an endocrine cause for the virilisation.

In generalised hypertrichosis there is accentuation of facial hair in the frontal, temporal, and preauricular regions. The eyebrows may be bushy or confluent. On the back of the trunk the hair converges on the midline, often forming whorls over the spine. ${ }^{1}$ It may occur as part of a syndrome or metabolic disorder ('symptomatic hypertrichoses') as opposed to 'congenital hypertrichosis' where markedly excessive hair growth is the most prominent feature.

While this review will focus on generalised hypertrichosis in childhood, it should be noted that localised hypertrichosis can occur and may be related to naevi or spina bifida occulta, previous trauma or chemical irritations, ${ }^{2}$ and in a few inherited conditions such as hairy elbows, hairy ears, hairy nose tip, or hairy palms and soles. ${ }^{3}$

Symptomatic hypertrichosis in childhood ASSOCIATION WITH DYSMORPHIC SYNDROMES A characteristic facial appearance in a child with hypertrichosis may lead to the recognition of one of a number of dysmorphic syndromes

Dr $v$ Haunersches

Children's Hospital, University of Munich, Germany

F A M Baumeister

H P Schwarz

Department of Genetics, Children's Centre Munich and University of Munich Institute for Social Paediatrics and Children's Medicine S Stengel-Rutkowski

Correspondence to: Dr F A M Baumeister, Dr v Haunersches Kinderspital der Universität München, Lindwurmstraße 4, D-80337 München, Germany.
Syndromes associated with generalised hypertrichosis

Brachmann-de Lange syndrome ${ }^{3}$ (MIM 122470)

Coffin-Siris syndrome ${ }^{3}$ (MIM 135900)

Rubinstein-Taybi syndrome ${ }^{3}$ (MIM 268600)

Seckel's syndrome ${ }^{3}$ (MIM 210600)

Cerebro-oculofacioskeletal syndrome ${ }^{3}$ (MIM 214150)

Gorlin's syndrome ${ }^{3}$ (MIM 233500)

Schinzel Giedion midface retraction syndrome ${ }^{3}$ (MIM 269150)

Barber Say syndrome 25

Hajdu Cheney syndrome ${ }^{3}$ (MIM 102500)

Weyers' acrofacial-dysostosis syndrome ${ }^{3}$ (MIM 193530)

Osteochondrodysplasia with hypertrichosis ${ }^{3}$ (MIM 239850)

Gingival fibromatosis with hypertrichosis ${ }^{3}$ (MIM 135400) Amaurosis congenita (cone-rod type) with hypertrichosis (MIM 204110)

Leprechaunism ${ }^{3}$ (MIM 147670, 246200)

Patterson's syndrome ${ }^{3}$ (MIM 169170)

Seip's syndrome ${ }^{3}$ (MIM 269700)

Partial trisomy 3q syndrome ${ }^{6}$

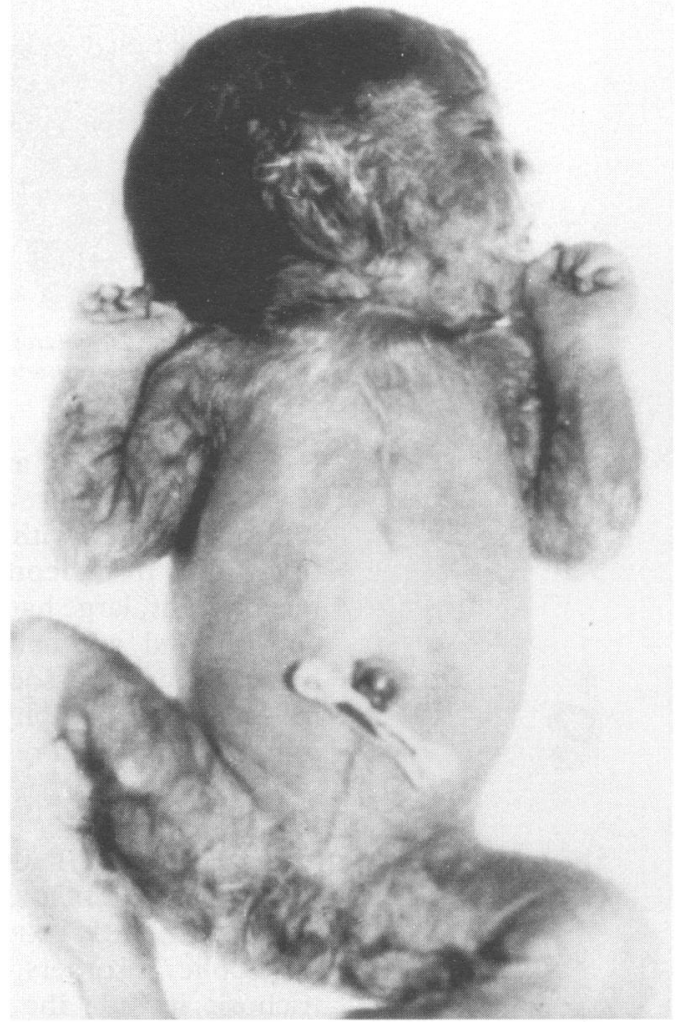

Figure 1 Ambras'syndrome in a newborn girl. Reproduced with permission from Baumeister et al. ${ }^{24}$

(table), for example Brachmann-de Lange syndrome, Coffin-Siris syndrome, RubinsteinTaybi syndrome, Seckel's syndrome, cerebrooculofacioskeletal syndrome, Gorlin's syndrome, Schinzel Giedion midface retraction syndrome, or Barber Say syndrome.

Association with acro-osteolysis may result in diagnosis of the Hajdu Cheney syndrome or postaxial polydactyly to diagnosis of the Weyers' acrofacial dysostosis syndrome. Hypertrichosis associated with osteochondrodysplasia or gingival fibromatosis may indicate the presence of other genetic entities. Association with photophobia may indicate amaurosis congenita (cone-rod type) with congenital hypertrichosis.

In the newborn hypertrichosis associated with markedly reduced subcutaneous fat may indicate a diagnosis of leprechaunism, a lethal condition which is also associated with an unusual facial appearance, severe intrauterine and postnatal growth retardation, and hyperinsulinaemia with hyperplasia of the pancreatic 


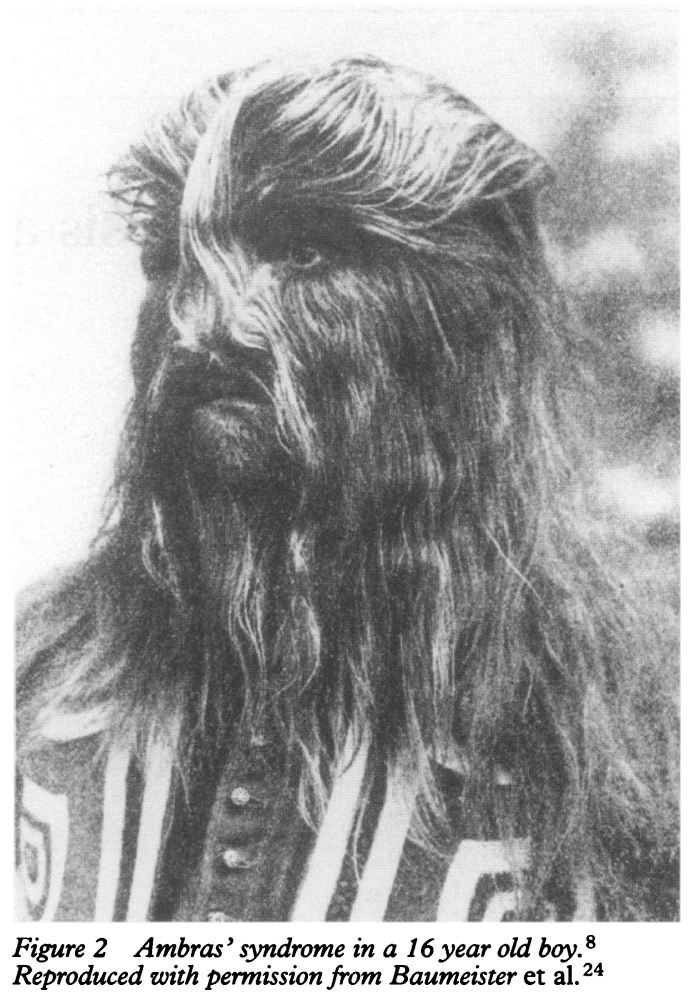

$\beta$ cells as a result of an insulin receptor defect. Pseudoleprechaunism (Patterson's syndrome) is also associated with hypertrichosis but is distinguished from leprechaunism by a normal birth weight, large hands and feet, cutis gyrata, and skeletal anomalies. In Seip's syndrome hypertrichosis is associated with lipodystrophy, muscular hypertrophy, increased stature and non-ketotic insulin resistant diabetes.

ASSOCIATION WITH METABOLIC OR CHROMOSOMAL DISORDERS OR PRENATAL AND POSTNATAL DRUG EXPOSURE

Metabolic disorders associated with hypertrichosis include the mucopolysaccharidoses, ${ }^{4}$ GM1-gangliosidosis, ${ }^{4}$ and porphyria. ${ }^{2}$ Among the chromosomal disorders, hypertrichosis is most prominent in partial trisomy $3 \mathrm{q}^{6}$ Hypertrichosis may also be a feature of patients with anorexia nervosa. ${ }^{2}$

Hypertrichosis may result from maternal alcohol abuse in pregnancy, ${ }^{4}$ as well as prenatal or postnatal exposure to hydantoin ${ }^{4}$ or minoxidil. ${ }^{7}$ Treatment with cyclosporin or diazoxide also leads to hypertrichosis, as does treatment with glucocorticoids.

\section{Congenital hypertrichosis}

Congenital hypertrichosis universalis is a very rare genetic condition in which the whole body is covered by excessive fine, light coloured hair that can reach a considerable length. ${ }^{89}$ The condition was erroneously thought to be associated with increased mortality because the first reported case of leprechaunism was described (and subsequently cited) as congenital hypertrichosis universalis. ${ }^{10-15}$ To confuse matters further, the terms congenital hypertrichosis universalis, congenital hypertrichosis lanuginosa, and hypertrichosis lanuginosa have been used synonymously, ${ }^{9} 111214$ 16-23 although they cover three different clinical entities. The three subtypes are believed to result from mutation of an autosomal dominant gene, but differ with regard to the persistence and pattern of hypertrichosis, and the associated anomalies.

In the Ambras' syndrome ${ }^{24}$ generalised hypertrichosis is present at birth (fig 1) and persists for life. The hair is most abundant on the face, ears, and shoulders (fig 2) and this becomes more accentuated with increasing age; this unique pattern allows differentiation from the other hypertrichosis syndromes. If not shaved the hair reaches a considerable length (fig 2). Abnormalities of the teeth, accessory nipples, and hexadactyly may be associated findings.

Transient congenital hypertrichosis universalis is present at birth but disappears during infancy and is characterised by generalised hypertrichosis which spares the face, hands and feet (fig 3). 181922 The condition was associated with a neonatal tooth in one report ${ }^{22}$ and with congenital glaucoma in another. ${ }^{19}$

In persistent hypertrichosis universalis affected subjects are only slightly hairy at birth but increasing hairiness occurs in infancy. ${ }^{912} 141620$ In contrast to Ambras' syndrome, the facial hair is not uniformly distributed but is accentuated in the frontal, temporal, and preauricular regions. No other associated abnormalities have been reported.

\section{Management of hypertrichosis}

The need for treatment depends on the degree of hypertrichosis and the resulting psychosocial

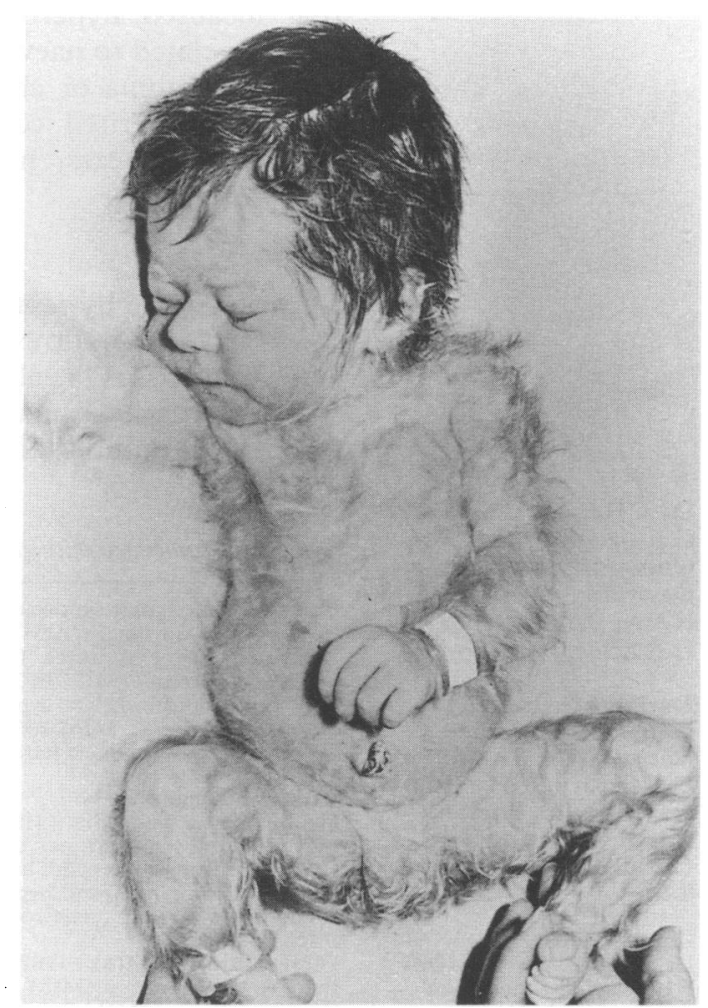

Figure 3 Transient congenital hypertrichosis universalis in a newborn girl. ${ }^{22}$ 
problems. In an excessively hairy newborn early removal of hair may be necessary because of difficulties the family may have in accepting the child, leading to social isolation. ${ }^{21} 2324$ Removal of hair is also needed to allow cleaning of the nappy area. ${ }^{22}$

There are several ways of removing hair. Chemical depilatories are effective but repeated use leads to irritation of the skin and may cause contact dermatitis. Wax epilation or depilatory plasters are painful and remove fine vellus hair which may induce transformation to coarse terminal hair, giving the impression of increased hairiness. ${ }^{2}$ Electrolytic destruction of individual hair papillae removes some hair permanently but up to $30 \%$ of the hair papillae treated in any one session regrow. ${ }^{2}$ There is also a risk of scarring after destruction of the deep dermal papillae. For these reasons electrolysis cannot be recommended in children with generalised hypertrichoses and repeated shaving remains the treatment of choice. ${ }^{91121-24}$

We thank Dr J Sigalas for the photograph in fig 1 and Dr J W Partridge for permission to reproduce fig 3.

1 Barth JH, Wilkinson JD, Dawber RPR. Prepubertal hypertrichosis: normal or abnormal? Arch Dis Child 1988; 63: 666-8.

2 Braun-Falco O, Plewig G, Wolff HH, Winkelmann RK. Dermatology. Berlin: Springer-Verlag, 1991.

3 Mc Kusick VA. Mendelian inheritance in man: catalogs of autosomal dominant, autosomal recessive and $X$-linked phenotypes. 10th Ed. Baltimore: The John Hopkins University Press, 1992

4 Bankier A, Aymé S, Sillence DO, Kozlowski K, Rogers M. POSSUM (pictures of standard syndromes and undiagnosed malformations). Melbourne, Australia: Murdoch Institute for Research into Birth Defects, Royal Children's

Hospital, 199

O'Brien JS. $\beta$-galactosidase deficiency (GM1 gangliosidosis, galactosialidosis, and Morquio syndrome type B); ganglioside sialidase deficiency (mucolipidosis IV). In: Scriver CR, Beaudet A, Sly WS, Valle D, eds. The metabolic basis of inherited disease. New York: McGraw-Hill,
1989: 1797-806.
6 Stengel-Rutkowski S, Murken JD, Pilar V, et al. New chromosomal dysmorphic syndromes. 3. Partial trisomy 3q. Eur F Pediatr 1979; 130: 111-25.

7 Kaler SG, Patrinos ME, Lambert GH, Myers TF, Karlman $R$, Anderson CL. Hypertrichosis and congenital anomalies associated with maternal use of minoxidil. Pediatrics 1987; 79: 434-6.

8 Luschan von F. Ein Haarmensch. Zeitschrift für Ethnologie 1907; 39: 425-9.

9 Beighton P. Congenital hypertrichosis lanuginosa. Arch Dermatol 1970; 101: 669-72.

10 Schachner LA, Hansen RC. Pediatric dermatology. Edinburgh: Churchill Livingstone, 1988.

11 Berres HH, Nitschke $R$. Vergleichende klinische und morphologische Untersuchungen zwischen einem Neugeborenen mit Hypertrichosis universalis und gleichalNeugeborenen mit Hypertrichosis universalis und gleichaltrigen hautgesunden

12 Felgenhauer WR. Hypertrichosis lanuginosa universalis. f Genet Hum 1969; 17: 1-44.

13 Janssen TAE, De Lange C. Familial congenital hypertrichosis totalis (trichostasis). Acta Paediatr 1945; 33: 69-78.

14 Suskind R, Esterly NB. Congenital hypertrichosis universalis. In: Bergsma D, ed. Birth defects. Original article series.Published for The National Foundation - March of Dimes. Baltimore: Williams and Wilkins, 1971; 8: 103-6.

15 Baumeister FAM. Leprechaunism (Donohue's syndrome) described as familial congenital hypertrichosis totalis. Acto Paediatr 1994; 83: 18.

16 Broster LR. Hypertrichosis a report of three cases. BMF 1950; i: 1171-4.

17 Cockayne EA. Inherited abnormalities of the skin and its appendages. London: Oxford University Press, 1933.

18 Gardner ALK. A case of hypertrichosis universalis. East Afr Med $\mathcal{7} 1964$; 41: 345-7.

19 Judge MR, Khaw PT, Rice NSC, Christopher A, Holmstrom G, Harper JI. Congenital hypertrichosis lanuginosa and congenital glaucoma. $\mathrm{Br} \mathcal{F}$ Dermatol 1991 ; 124: 495-7.

20 Kint AHEE, Vermander FRM, Decroix JMA. Kongenitale Hypertrichosis lanuginosa. Der Hautarzt 1985; 36: 423-4.

21 Nowakowski TK, Scholz A. Das Schicksal behaarter Menschen im Wandel der Geschichte. Der Hautarzt 1977; 28: 593-9.

22 Partridge JW. Congenital hypertrichosis lanuginosa: neonatal shaving. Arch Dis Child 1987; 62: 623-5.

23 Sigalas J, Tabakis T, Skordala M, Nouri M. Congenital hypertrichosis universalis. Pediatrica Chronica 1990; 17: 181-5.

24 Baumeister FAM, Egger J, Schildhauer MT, StengelRutkowski S. Ambras syndrome: delineation of a unique hypertrichosis universalis congenita and association with a balanced pericentric inversion (8) (p11.2;q22). Clin Genet 1993; 44: 121-8.

25 Martinez-Santana S, Perez-Alvarez F, Frias JL, MartinezFrias ML. Hypertrichosis, atrophic skin, ectropion, and Frias ML. Hypertrichosis, atrophic skin, ectropion, and
macrostomia (Barber-Say syndrome): report of a new case. Am $\mathcal{F}$ Med Genet 1993; 47: 20-3. 